\title{
Benefit-cost analysis and the linear hypothesis
}

Alvin M. Weinberg, Director of the Institute for Energy Analysis at Oak Ridge, Tennessee warns against a common pitfall of administrators when trying to make cost/benefit analyses of new technologies

ECONOMICS is indeed the dismal science. This was brought home to me as I read the recent report (BEIR-II) of the US National Academy of Sciences, 'Considerations of Health Benefit-Cost Analysis for Activities Involving Ionising Radiation Exposure and Alternatives'. This is a sequel to the 1972 report on Biological Effects of Ionising Radiation (BEIR-I), a study that has been as widely misinterpreted and misused as any the National Academy has issued.

Benefit-cost analysis is simple in principle. In judging whether mass $x$-ray screening or nuclear power or therapeutic $\mathrm{x}$-rays are worthwhile, one tots up the benefits--early detection of cancers, cheaper electricity, extended life span-and the costs: higher incidence of cancer or genetic disease induced by radiation. If the benefits exceed the costs, the technology is acceptable; if not it is unacceptable-QED.

Unfortunately the measures of cost (human health) and benefit (electricity) are not the same; or much worse, where the exposures are very small, the very question of estimating costs becomes essentially trans-scientific. At least at our present stage of scientific knowledge, and possibly forever, we cannot estimate the carcinogenic or genetic effect of 1 mrem of ionising radiation.

But the economists, not to say administrators, demand a neat cost/benefit calculus. This requires that a common measure, dollars per life, be used for costs and benefits; and this further requires that the vast uncertainties, even uncertainties in principle, as to the effects of low levels of ionising radiation, be obliterated by a stroke of administrative science.

That stroke of administrative scientific ingenuity is the assumption that the linear hypothesis holds down to zero dose (in other words that the biological effect is proportional to dose regardless of the size of dose or the rate of exposure), and the inevitable introduction of the unit 'person-rem'-the product of the number of individuals exposed and the dose in rems to each individual. Having brushed aside the profound illogicalities in the use of the person-rem as an estimator of actual biological damage, the economists and administrators have made the problem tractable: assign so many dollars per person-rem as the cost, so many dollars per life saved, and the cost/benefit calculus is saved.

That nonsense, of course, lies in the use of the person-rem as an estimator of damage. Curiously, the body of the BEIR-I report cautions against so using the person-rem; but the summary, possibly written by someone other than the authors of BEIR-I, in effect uses the person-rem to place bounds on the number of cancers induced by very low level exposure of large populations. BFIR-II takes up where BEIR-I left off, and unfortunately does not re-examine the validity of the original assumption concerning the use of the person-rem as an estimator of damage.

Nevertheless, in a perceptive paragraph in what I thought was the report's best chapter 'Lcgal and institutional aspects of using benefit-cost analysis to control ionising radiation', one reads "Serious question should be given to the adoption of alternatives to traditional cconomic benefit-cost analysis for such regulatory decision-making .... One possible alternative is an appropriately comprehensive cost-effectiveness analysis ... (that) requires the articulation of objectives, the weighing of the alternative means to achieve these objectives, and the selection of the least costly approach". Thus, instead of performing magical balancing acts with largely indeterminate costs weighed against incommensurable and equally indeterminate benefits, concede the arbitrary, political nature of the objective at the outset--agree on an appropriately small level of radiation insult that is tolerable, and then go about devising a technology that will meet that objective as cheaply as possible.

A hint as to what the "appropriately small level of insult" should be was given in the 1958 report of the Ad Hoc Committee of the National Committee on Radiation Protection (The Friedell Report Science, 131, 482; 1960). Since the biosphere has evolved in the presence of a natural background of radiation, Friedell asked whether man-made radiation ought to be judged tolerable if it were 'small' compared to this background. This very sensible suggestion was never followed up-instead, we introduced the nonsensical person-rem and strict linear hypothesis, and continued to juggle indeterminate costs and benefits.

To be sure, the definition of 'small' compared to natural background is arbitrary, but at least the arbitrariness is explicit. H. I. Adler, the former director of the Biology Division of Oak Ridge National Laboratory, has suggested (Health Physics, in press) that 'small' be taken as the standard deviation of the population-weighted natural background. This amounts, in the United States, to about 20 mrads per year of gamma radiation, and somewhat miraculously, is close both to the EPA emission standard for the nuclear fuel cycle and the NRC standard for emissions from nuclear power plants. The suggestion has been taken up by the American Physical Society's Committee on the Nuclear Fuel Cycle; they point out that if Adler's standard were adopted, then the actual exposures will average to something small compared to the variability in background.

Adler's suggestion amounts to cutting the Gordian knot: proving or disproving the linear hypothesis at very low exposure. The observed incidence of leukemia at Nagasaki persuades me that linearity, with slope determined by the incidence of leukemia at high dose, is inconsistent with the data. Others have looked at various bits of data and insist they see straight lines that go through the origin. But the bald fact is that linearity, upon which the apparatus of cost/benefit anaiysis for ionising radiation now largely rests, is, for low doses, simply an unproven, probably unprovable hypothesis. I think something like Adler's idea is a far more logical approach to standard setting.

I wax rather vehement because the use of person-rem as an estimator of damage at low dose has badly warped the nuclear debate, and it may have the same effect on the debate over the use of diagnostic x-rays. Thus most of the estimated casualties from a bad nuclear accident are found in the large dispersed population exposed to small doses of radiation. In the original Rasmussen report on reactor safety, credit was therefore given for low doses and dose rates (the strict linear hypothesis was rejected), but the critics insist on using the strict linear hypothesis. BEIR-II, despite the disclaimer previously quoted, recommends that "national policies involving activities such as nuclear power production and medical uses of radiation should be guided to the extent possible by health benefit-cost analysis"; and throughout the report strict linearity is assumed. Why could not this second BEIR report help undo the vast damage caused by the widespread misunderstanding of the first BEIR report, and state, clearly and explicitly, that the use of the person-rem as an estimator of damage is bad science, and this leads to bad policy? I believe BEIR-II must be judged a failure in not having taken the opportunity to correct this unfortunate and widespread misuse of its predecessor report. 